\title{
Author Correction: A complex human gut microbiome cultured in an anaerobic intestine-on-a-chip
}

Sasan Jalili-Firoozinezhad (D), Francesca S. Gazzaniga, Elizabeth L. Calamari, Diogo M. Camacho, Cicely W. Fadel, Amir Bein (D), Ben Swenor (D), Bret Nestor, Michael J. Cronce, Alessio Tovaglieri, Oren Levy, Katherine E. Gregory, David T. Breault, Joaquim M. S. Cabral, Dennis L. Kasper (iD, Richard Novak and Donald E. Ingber (iD)

Correction to: Nature Biomedical Engineering https://doi.org/10.1038/s41551-019-0397-0, published online 13 May 2019.

In the version of this Article originally published, the authors mistakenly cited Fig. $5 \mathrm{~d}$ in the sentence beginning 'Importantly, the microbiome cultured in these primary Intestine Chips...; the correct citation is Supplementary Table 2. This has now been amended.

Published online: 18 June 2019

https://doi.org/10.1038/s41551-019-0428-x 